\title{
Journal of the American Chemical Society
}

\section{Orthogonal recognition processes drive the assembly and replication of a [2]rotaxane}

\author{
Tamara Kosikova ${ }^{a}$, Nurul Izzaty Hassan ${ }^{\text {ab }}$, David B. Cordes ${ }^{a}$, \\ Alexandra M. Z. Slawin ${ }^{a}$ and Douglas Philp ${ }^{* a}$
}

\footnotetext{
${ }^{a}$ School of Chemistry and EaStCHEM, University of St Andrews, North Haugh, St Andrews, KY16 9ST, United Kingdom

${ }^{b}$ School of Chemical Sciences and Food Technology, Faculty of Science and Technology, Universiti Kebangsaan Malaysia, 43600 Bangi, Selangor, Malaysia

Corresponding author: d.philp@st-andrews.ac.uk
}

\begin{abstract}
Within a small interconnected reaction network, orthogonal recognition processes drive the assembly and replication of a [2]rotaxane. Rotaxane formation is governed by a central, hydrogen bonding-mediated binding equilibrium between a macrocycle and a linear component, which associate to give a reactive pseudorotaxane. Both the pseudorotaxane and the linear component undergo irreversible, recognitionmediated 1,3-dipolar cycloaddition reactions with a stoppering maleimide group, forming rotaxane and thread, respectively. As a result of these orthogonal recognition-mediated processes, the rotaxane and thread can act as autocatalytic templates for their own formation and also operate as crosscatalytic templates for each other. However, the interplay between the recognition and reaction processes in this reaction network results in the formation of undesirable pseudorotaxane complexes, causing thread formation to exceed rotaxane formation in the current experimental system. Nevertheless, in the absence of competitive macrocycle-binding sites, realization of a replicating network favoring formation of rotaxane is possible.
\end{abstract}




\section{Introduction}

Molecular recognition plays a pivotal role in the self-assembly ${ }^{1}$ and self-organization ${ }^{2}$ of both synthetic chemical systems and those found in Nature. The constitution of individual components within interconnected networks present in such systems governs their capacity to perform specific functions and to interact with other species in a recognition-mediated fashion. Small changes in the identity or orientation of recognition-enabling structural elements can have profound effects ${ }^{3}$ on the recognition processes within a network. Therefore, careful consideration has to be given to both the desirable function-encoding elements, as well as their relative position within a given molecular structure. Through controlled design, we can exploit the potential of molecular recognition and self-assembly as driving forces for the fabrication ${ }^{4}$ of complex systems in a pre-organized manner. In the past, molecular recognition has been employed successfully in the formation of numerous molecular assemblies ${ }^{5}$, mechanically-interlocked architectures $^{6}$, nanoscale machines ${ }^{7}$ and systems capable of transferring structural information ${ }^{8}$ through self-replication. Specifically, we are interested in exploring the underlying requirements that give rise to chemical systems capable of exhibiting phenomena such as self-replication. A better understanding of the principles governing assembly and replication in chemical systems will allow us to probe the requirements for molecular evolution ${ }^{9}$ and emergence ${ }^{10}$ of complex function. The minimal requirements for non-enzymatic, recognition-mediated replication are well understood, with a number of small-molecule examples reported ${ }^{11}$ in the literature. However, the requirements for integrating self-replication with other recognition-mediated processes, such as those required for assembly of mechanically-interlocked architectures, remains a largely unexplored area. Previously, we have described $^{12}$ a kinetic framework for integrating replication with the synthesis of a mechanically-interlocked architecture, namely a rotaxane. However, the experimental implementations of this design have not yet afforded a functional self-replicating rotaxane. Here, we propose an alternative kinetic model for the creation of a system where the assembly and replication of a [2]rotaxane is driven by two orthogonal recognition processes.

Designing a molecule capable of self-replication requires two building blocks, here termed the linear component $\mathbf{L}$ and the stoppering species $\mathbf{S}$, equipped with complementary recognition and reactive sites. Reaction of these components (Figure 1, centre) produces a template $\mathbf{T}$. This template is capable of binding components $\mathbf{L}$ and $\mathbf{S}$ in a recognition-mediated, catalytically-active ternary complex $[\mathbf{T} \cdot \mathbf{L} \cdot \mathbf{S}]$, thereby accelerating the reaction to form $\mathbf{T}$ (Figure 1, top left). Ultimately, the resulting product duplex $[\mathrm{T} \cdot \mathrm{T}]$ dissociates to afford two template molecules capable of taking part in further template-mediated replication cycles. Formation of a rotaxane with the capacity to replicate, however, requires an additional binding site in order to enable association between macrocyclic component $\mathbf{M}$ and one of the building blocks required for self-replication. In this case, the linear component $\mathbf{L}$ bears the additional macrocyclebinding site, enabling formation of a reactive pseudorotaxane complex $[\mathbf{L} \cdot \mathbf{M}]$ (Figure 1 , centre). The replicating network radiates from this central equilibrium, established through the association of the macrocycle $\mathbf{M}$ and the linear component $\mathbf{L}$, into separate, yet interconnected thread and rotaxane forming 
catalytic cycles. Both linear component $\mathbf{L}$ and pseudorotaxane complex $[\mathbf{L} \cdot \mathbf{M}]$ can react with stoppering species $\mathbf{S}$ to afford thread $\mathbf{T}$ and rotaxane $\mathbf{R}$, respectively. $\mathbf{T}$ and $\mathbf{R}$ can both establish autocatalytic cycles, proceeding via the formation of catalytically active ternary complex, $[\mathbf{T} \cdot \mathbf{L} \cdot \mathbf{S}]$ to make thread $\mathbf{T}$ (Figure 1, top left) and quaternary complex, $[\mathbf{R} \cdot \mathbf{L} \cdot \mathbf{M} \cdot \mathbf{S}]$, to create rotaxane $\mathbf{R}$ (Figure 1, bottom left). The rotaxane and thread templates also satisfy the structural and recognition requirements necessary for taking part in crosscatalytic cycles, proceeding through $[\mathbf{R} \cdot \mathbf{L} \cdot \mathbf{S}]$ and $[\mathbf{T} \cdot \mathbf{L} \cdot \mathbf{M} \cdot \mathbf{S}]$ complexes (Figure 1 , top right and bottom right, respectively). Overall, this interconnected replicating network can operate through two autocatalytic and two crosscatalytic cycles. We envisaged that implementation of orthogonal recognition processes would permit the formation of a system where all catalytic cycles are active.

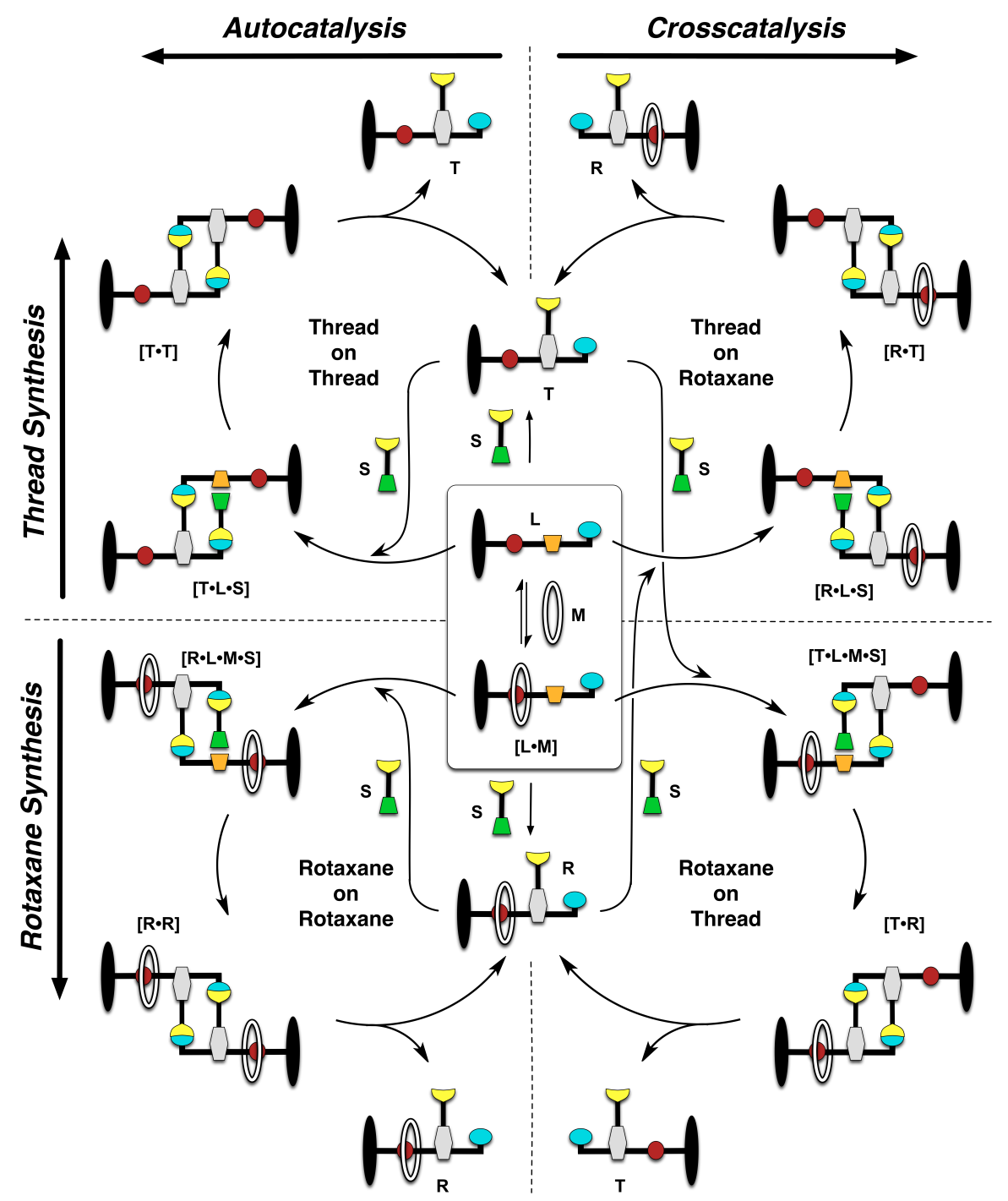

Figure 1. A kinetic model describing the main interactions in a replicating network with orthogonal recognition processes, leading to the formation of thread $\mathbf{T}$ and rotaxane $\mathbf{R}$. The interconnected network is based around a central equilibrium (solid rectangle) between linear component $\mathbf{L}$ and macrocycle $\mathbf{M}$, to give reactive pseudorotaxane complex [ $\mathbf{L} \cdot \mathbf{M}]$. The network branches out into autocatalytic thread (top left) and rotaxane (bottom left) cycles, and crosscatalytic thread (top right) and rotaxane (bottom right) cycles. For simplicity, equilibrium arrows are not shown outside of the central equilibrium. Reactive and recognition elements are represented in cartoon form: blue and yellow represent complementary recognition sites, orange and green denote reactive elements, grey represent the reaction product and macrocycle-binding site is shown in dark red. 
Our design (Figure 2) of the key quaternary $[\mathbf{R} \cdot \mathbf{L} \cdot \mathbf{M} \cdot \mathbf{S}]$ complex exploits $\mathrm{H}$-bonding mediated recognition for both macrocycle binding and the complementary recognition units required for self-replication. Specifically, we exploited the recognition between a phenylacetic acid, located on the stoppering component S, and a 6-methyl-2-amidopyridine unit on linear component $\mathbf{L}$ (Figure 2a), which we have successfully employed ${ }^{8 d, 13}$ in several self-replicating systems in the past. Similarly, we have utilized a 1,3dipolar cycloaddition reaction between a nitrone, here positioned on linear component $\mathbf{L}$, and a maleimide on stoppering element $\mathbf{S}$, as the means of irreversibly connecting the starting building blocks into a template Thread molecule (Figure $2 \mathrm{~b}$ ). From previous experience, we believed that a biphenyl spacer between the nitrone reactive site and the macrocycle binding site would be sufficient for isolating the macrocycle from the reactive site, thus preventing potential steric issues ${ }^{12}$, which would hinder the cycloaddition. The recognition event used to associate the macrocyclic and linear component in the pseudorotaxane complex $[\mathbf{L} \cdot \mathbf{M}]$ is provided by $\mathrm{H}$-bonding mediated recognition between an amide group on the linear component and complementary recognition units on the macrocycle. We utilized two structurally similar macrocycles for the formation of our rotaxane (Figure 2): macrocycle GM employed ${ }^{14}$ previously, containing a glycol spacer, and macrocycle $\mathbf{P M}^{15}$, incorporating a pyridine linker. Once the pseudorotaxane complex is formed, the irreversible reaction locks the macrocycle on the linear component through the stoppering approach, resulting in GM [2]Rotaxane and PM [2]Rotaxane (Figure $2 b)$. Once the concentration of template present in the reaction mixture is sufficient to initiate a catalytic cycle, the reaction proceeds through the recognition-mediated replication channel (Figure 2c), with high diastereoselectivity.

\section{Results and Discussion}

We, and others, have established ${ }^{12,16}$ previously that various substituted diarylamides are capable of associating with macrocycle $\mathbf{G M}$, demonstrating that the amide-containing linear component $\mathbf{L}$ is likely to be a suitable binding partner. Macrocycle PM contains a second pyridine ring with $\mathrm{H}$-bond acceptor abilities, which we expected to bind more strongly, affording a system more selective towards the formation of a rotaxane. Initially, we performed ${ }^{1} \mathrm{H}$ NMR spectroscopic binding studies examining the association between each macrocycle and a model compound $\mathbf{N}$, equipped with a terminal $-\mathrm{NO}_{2}$ group in place of the nitrone reactive site (Figure 3). The desired amide-binding site is therefore present in isolation from any other potential recognition or reactive moieties. By reducing the temperature to $233 \mathrm{~K}$, the macrocycle-linear component equilibrium enters the slow exchange regime on the NMR chemical shift timescale, thus enabling direct observation of resonances corresponding to unbound species and the pseudorotaxane complex. For illustrative purposes, we will discuss only the complex formed between the compound $\mathbf{N}$ and the macrocycle $\mathbf{G M}$ (the formation of other pseudorotaxane complexes is discussed in the SI). Particularly diagnostic of pseudorotaxane formation is the downfield shift of the resonance arising from the macrocycle $\mathrm{NH}$ protons (Figure $\left.3 \mathrm{~b}, \mathrm{H}^{\mathrm{g}}\right)(+1.49 \mathrm{ppm}$ ). The chemical shift of the macrocycle $\mathrm{NH}$ resonance in the bound complex $(9.42 \mathrm{ppm})$ suggests that these protons are hydrogen bonded to the 
carbonyl of the amide present in $\mathbf{N}$. Macrocycle resonances arising from $\mathrm{H}^{\mathrm{d}}$ and $\mathrm{H}^{\mathrm{e}}$ are also shifted upfield (-0.66 and -0.56 ppm respectively)

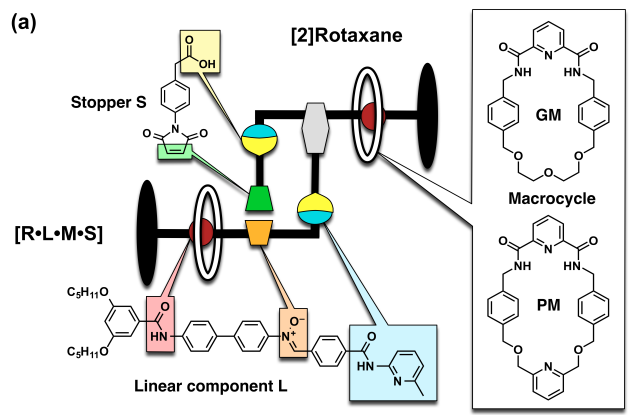

(b)
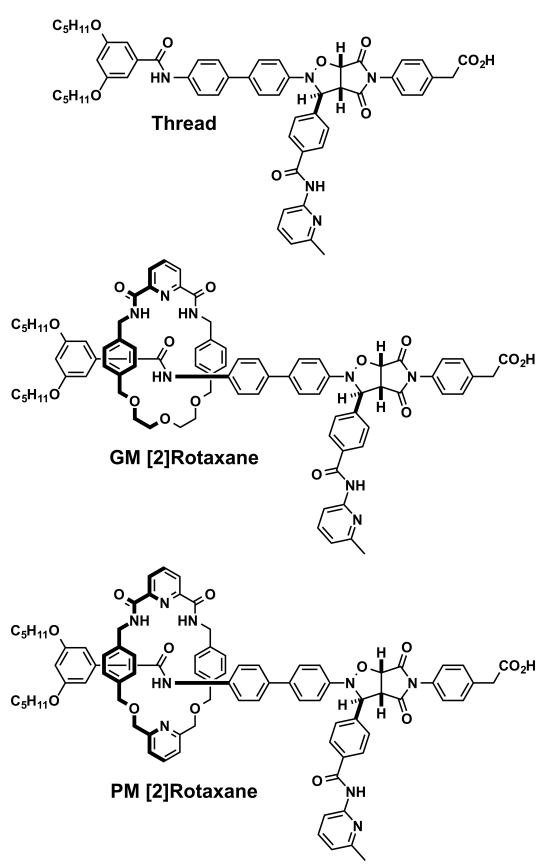

(c)

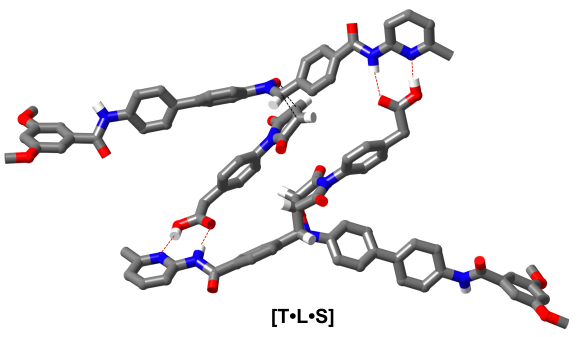

Figure 2. (a) Cartoon representation of the chemical building blocks employed in the design of a self-replicating [2]rotaxane. The amide macrocycle-binding site (dark red) enables formation of a pseudorotaxane [L・M]. Amidopyridine (blue) and a carboxylic acid (yellow) recognition sites facilitate recognition-mediated self-replication through the formation of a quaternary $\operatorname{complex}[\mathbf{R} \cdot \mathbf{L} \cdot \mathbf{M} \cdot \mathbf{S}]$, while the nitrone reactive site (orange) on the pseudorotaxane reacts with the maleimide (green) on the stoppering element to give the final [2]rotaxane. (b) Chemical structures of Thread, GM [2]Rotaxane and PM [2]Rotaxane. (c) Computed transition state geometry (RM1, MOPAC 2012) for Thread being made from $\mathbf{L}$ and $\mathbf{S}$ Thread (shown as stick representation, where carbon atoms are shown in dark grey, oxygen atoms in red, nitrogen atoms are in blue and hydrogen atoms in pale grey). Most hydrogen atoms are omitted for clarity. Red dashed lines represent $\mathrm{H}$-bonds mediating the assembly of the ternary complex. Black dashed lines denote the $\mathrm{C}-\mathrm{O}$ and $\mathrm{C}-\mathrm{C}$ bonds partially formed in the transition state (For details, see $\mathrm{ESI}$ ). 

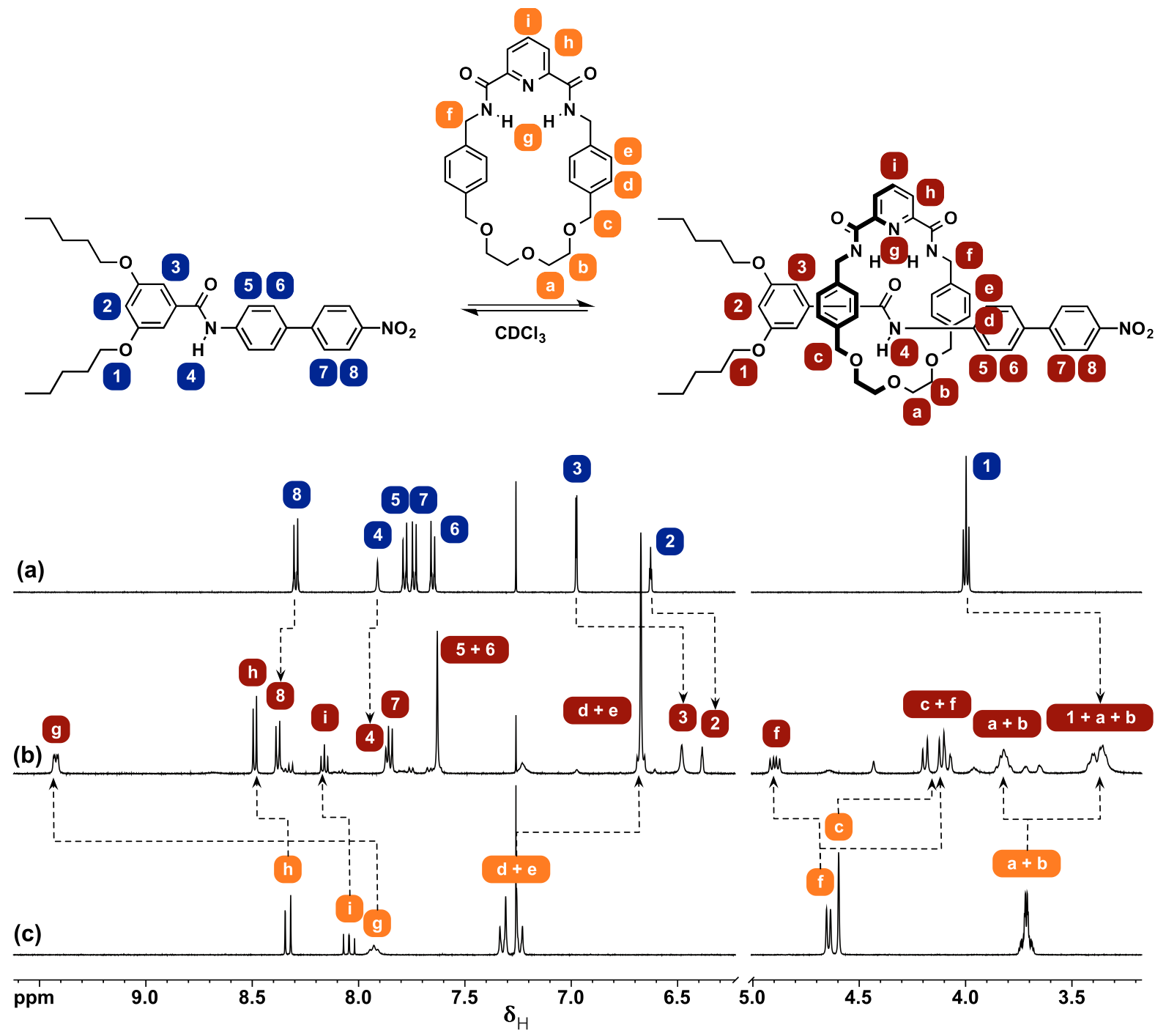

Figure 3. Partial ${ }^{1} \mathrm{H}$ NMR ( $500.1 \mathrm{MHz}, \mathrm{CDCl}_{3}$ ) of (a) compound $\mathbf{N}(\mathrm{RT})$ ), (b) equimolar mixture of $\mathbf{N}$ compound and $\mathbf{G M}$ (233 K), (c) GM (RT). Dashed lines are shown to connect resonances belonging to specific protons in bound and unbound states. Unassigned resonances arise from the unbound species.

The inequivalence of the resonances arising from the methylene protons in the $\mathrm{CH}_{2}$ group $\left(\mathrm{H}^{\mathrm{a}}, \mathrm{H}^{\mathrm{b}}\right.$ and $\left.\mathrm{H}^{\mathrm{c}}\right)$ on the macrocycle in the pseudorotaxane is a result of the end-to-end asymmetry imposed on the macrocycle by complexation with the model linear compound $\mathbf{N}$. Low temperature ${ }^{1} \mathrm{H}$ NMR spectroscopy further allowed single-point determination of association constants with both macrocycles, affording $K_{a}$ values of $3750 \mathrm{M}^{-1}$ for complex $\left[\mathrm{N} \cdot \mathrm{GM}\right.$ ] and $5100 \mathrm{M}^{-1}$ for complex [N•PM] at $223 \mathrm{~K}$. For pseudorotaxane [N•PM], we confirmed the location of the macrocycle at the expected binding site on $\mathbf{N}$ by low temperature $(223 \mathrm{~K}){ }^{1} \mathrm{H}-{ }^{1} \mathrm{H}$ ROESY experiments (for details, see $\mathrm{SI}$ ), which showed rOe cross peaks between the resonances associated with the $\mathrm{NH}$ protons $\left(\mathrm{H}^{7}\right)$ of the macrocycle and the two phenyl rings $\left(\mathrm{H}^{3}\right.$ and $\left.\mathrm{H}^{5}\right)$ on each side of the amide present in $\mathbf{N}$, and the resonances arising from the macrocycle $\mathrm{CH}_{2}$ protons and the resonance associated with the $\mathrm{NH}$ of $\mathbf{N}$. Next, we examined the association of each macrocycle with linear component $\mathbf{L}$, which, in addition to the macrocycle-binding amide site, also 
contains a nitrone and an amidopyridine, to which the macrocycles may potentially bind. The nitrone moiety in particular possesses a negatively charged oxygen atom with the potential ${ }^{17}$ to be a hydrogen bond acceptor in the presence of complementary recognition units. The low temperature ${ }^{1} \mathrm{H}-{ }^{1} \mathrm{H}$ ROESY NMR experiments, however, did not afford sharp resonances and calculation of association constants was therefore not possible from these data. Despite these limitations, there is clear evidence for association between $\mathbf{L}$ and $\mathbf{M}$, suggesting that the system may be suitable for rotaxane formation.

In order to confirm successful formation of thread $\mathbf{T}$ and the two rotaxanes, GM [2]rotaxane (GM-R) and PM [2]rotaxane (PM-R), we synthesized these products on a preparative scale by low temperature reaction of linear component $\mathbf{L}$ and stopper $\mathbf{S}$ in the presence of excess macrocycle. All three components, T, GM-R and PM-R, were isolated successfully by reverse phase flash column chromatography. Initially, we confirmed the identity of our products by MALDI-TOF mass spectrometry and ${ }^{1} \mathrm{H}$ and ${ }^{13} \mathrm{C}$ NMR spectroscopy. In order to further confirm that $\mathbf{G M}-\mathbf{R}$ and PM-R contained the macrocycles bound at the expected site, we obtained single crystals ${ }^{18}$ suitable for X-ray crystallographic analysis (for details, see ESI). The X-ray analyses confirmed the expected molecular structures in both $\mathbf{G M}-\mathbf{R}$ and $\mathbf{P M}-\mathbf{R}$, in particular the trans stereochemistry of the isoxazolidine ring, and the location of each macrocycle on the linear component, mediated by $\mathrm{H}$-bonding interactions between the macrocycle $\mathrm{NH}$ and the carbonyl of the linear component (Figure 4). For both $\mathbf{G M}-\mathbf{R}$ and PM-R, The crystal lattice of both rotaxanes contained a racemic mixture of the trans diastereoisomeric cycloadduct (Figure 4), where two molecules typically interact through hydrogen bonding between one $-\mathrm{COOH}$ and one amidopyridine recognition site, forming $\mathrm{H}$-bonded chains running along the $b$-axis (GM-R) or c-axis (PM-R). Interestingly, the phenylacetic acid moiety present in the rotaxanes was directed towards the pyridine ring of each macrocycle in both GM-R and PM-R. 
(a) (i)

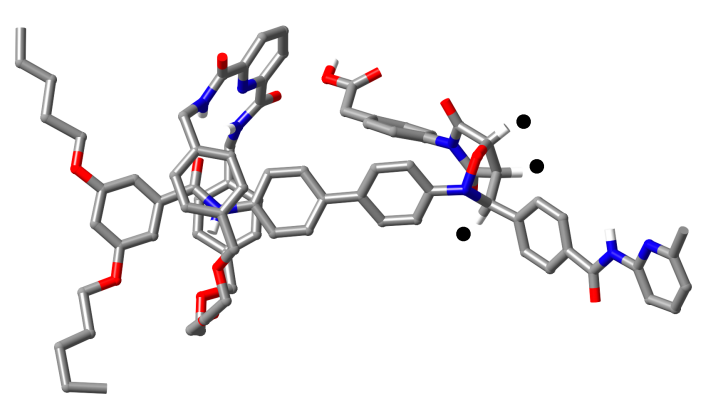

(b) (ii)

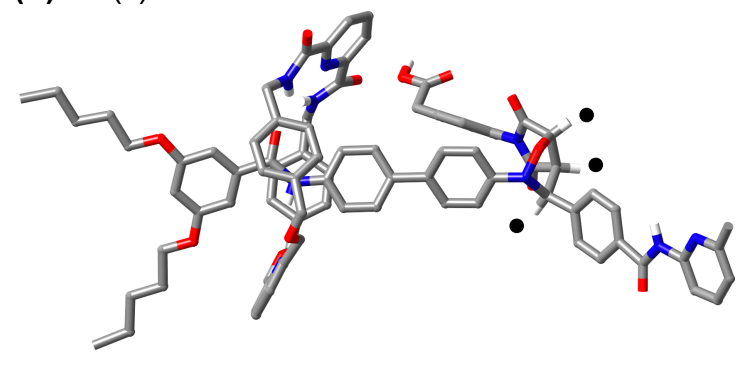

(i)

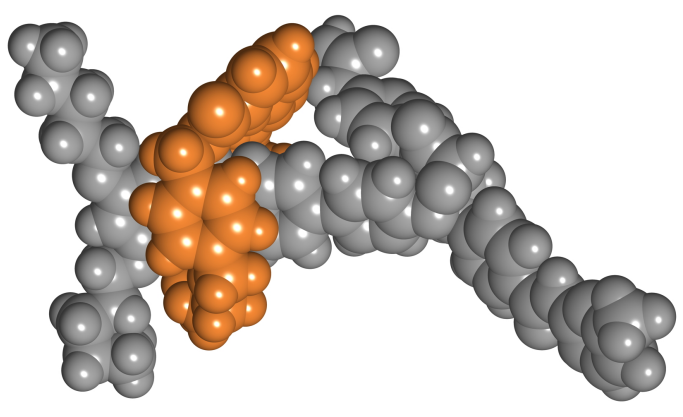

(ii)

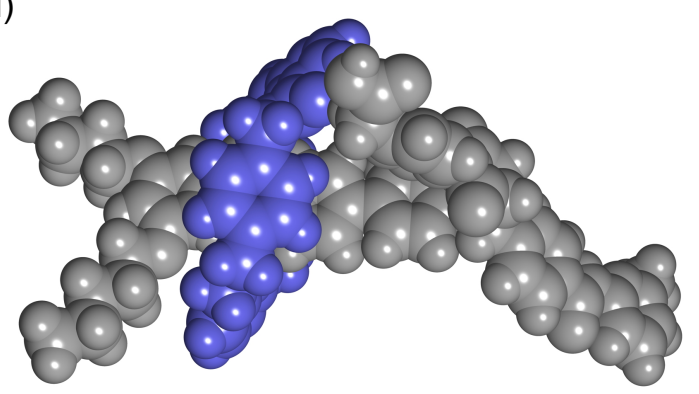

Figure 4. Stick (i) and space-fill (ii) representations of the X-ray crystal structure of (a) GM [2]rotaxane and (b) PM [2]rotaxane as determined by single-crystal X-ray crystallography. In the stick representations, carbon atoms are shown in grey, oxygen atoms in red, nitrogen atoms in blue and hydrogen atoms are shown in white. Most hydrogen atoms are omitted for clarity. Black circles in the rotaxane stick representations highlight the relative trans stereochemistry of the isoxazolidine ring protons. In the space fill representations, the thread component is colored grey and the macrocycle is colored either orange (GM) or blue (PM).

We conducted two-dimensional ${ }^{1} \mathrm{H}-{ }^{1} \mathrm{H}$ ROESY experiments at room temperature in order to establish the location of the macrocycle in both GM-R and PM-R on the linear component in solution. Figure 5 shows the rOe cross peaks observed in the 2D ROESY NMR spectrum of GM-R. Particularly diagnostic are the highlighted cross peaks associating the resonances arising from the macrocycle $\mathrm{H}^{\mathrm{a}}, \mathrm{H}^{\mathrm{b}}$ and $\mathrm{H}^{\mathrm{c}}$ protons with the resonances arising from the $\mathrm{H}^{1}$ and $\mathrm{H}^{3}$ protons on the linear component, confirming the expected location of GM macrocycle on the thread in solution. Similar results were obtained for the PM-R (for details, see ESI). 


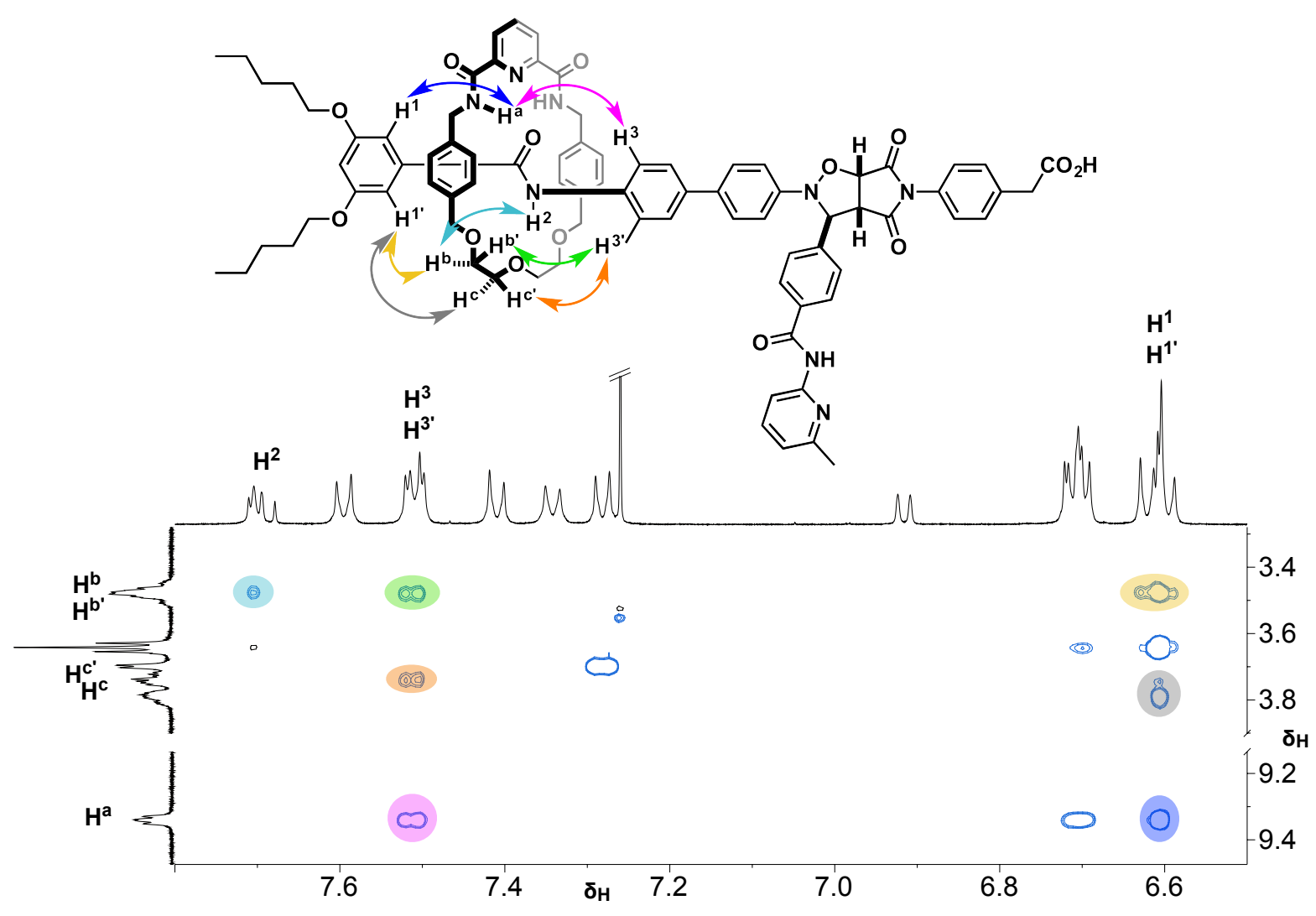

Figure 5. Partial ${ }^{1} \mathrm{H}-{ }^{1} \mathrm{H}$ ROESY correlation $\left(500.1 \mathrm{MHz}, \mathrm{CDCl}_{3}, \mathrm{RT}, 500 \mathrm{~ms}\right.$ mixing time) of GM [2]Rotaxane. Highlighted rOe cross peaks represent the through space interactions between linear component and the macrocycle. Unassigned cross peaks represent intra-component interactions.

Having synthesized and fully characterized thread $\mathbf{T}$ and both rotaxanes $\mathbf{G M}-\mathbf{R}$ and PM-R successfully, we were ready to undertake a comprehensive kinetic analysis in order to ascertain which catalytic cycles (see Figure 1) are active in our rotaxane:thread system. Initially, we examined the formation of thread $\mathbf{T}$ in the absence of any added template. An equimolar mixture containing the desired components $([\mathbf{L}]=[\mathbf{S}]=10 \mathrm{mM})$ was prepared in $\mathrm{CDCl}_{3}$ and the reaction progress at $5{ }^{\circ} \mathrm{C}$ was monitored by ${ }^{1} \mathrm{H}$ NMR (500.1 MHz) spectroscopy every 15 minutes over 8 hours. This low reaction temperature was selected for the kinetic experiments because it maximizes the strength of recognition-mediated processes within the system while simultaneously allowing accurate monitoring of the reaction progress on a reasonable timescale by ${ }^{1} \mathrm{H}$ NMR spectroscopy. The reaction time course (Figure 6a) for this reaction was determined by examining the resonances for the three protons associated with the trans isoxazolidine ring of the cycloadduct relative to 2,4-dinitrotoluene as an internal standard. We found that, following an initial lag period, typical for self-replicating systems, the thread replicated very efficiently, exhibiting a clear sigmoidal rate profile where the thread concentration reached $9.1 \mathrm{mM}$ after 4 hours ( $91 \%$ conversion). We determined the rate for this reaction $(\mathrm{d}[\mathrm{T}] / \mathrm{dt})$ by computing the first derivative of a seventh-order polynomial fitted to the concentration vs time data. The trans diastereoisomer was formed exclusively, with the rate maximum observed after 63 minutes $\left(4.1 \mathrm{mM} \mathrm{h}^{-1}\right)$. Next, we examined the autocatalytic 
formation of thread in the presence of instructing thread template. The required starting components ([L] $=[\mathbf{S}]=10 \mathrm{mM})$ and pre-formed thread $(10 \mathrm{~mol} \%)$ were dissolved in $\mathrm{CDCl}_{3}$ and the reaction progress was followed by ${ }^{1} \mathrm{H}$ NMR spectroscopy as described previously. Addition of pre-formed thread at $t=0$ resulted in the disappearance of the lag period (Figure 6a), allowing the system to reach its maximum rate $(6.0$ $\mathrm{mM} \mathrm{h}^{-1}$ ) from the beginning of the reaction (Figure $6 \mathrm{~b}$ ), thereby confirming the successful design of our self-replicating system ${ }^{19}$. With this information in hand, we analyzed thread formation in the presence of 10 mol\% preformed GM-R and PM-R (Figure 6a).

(a)
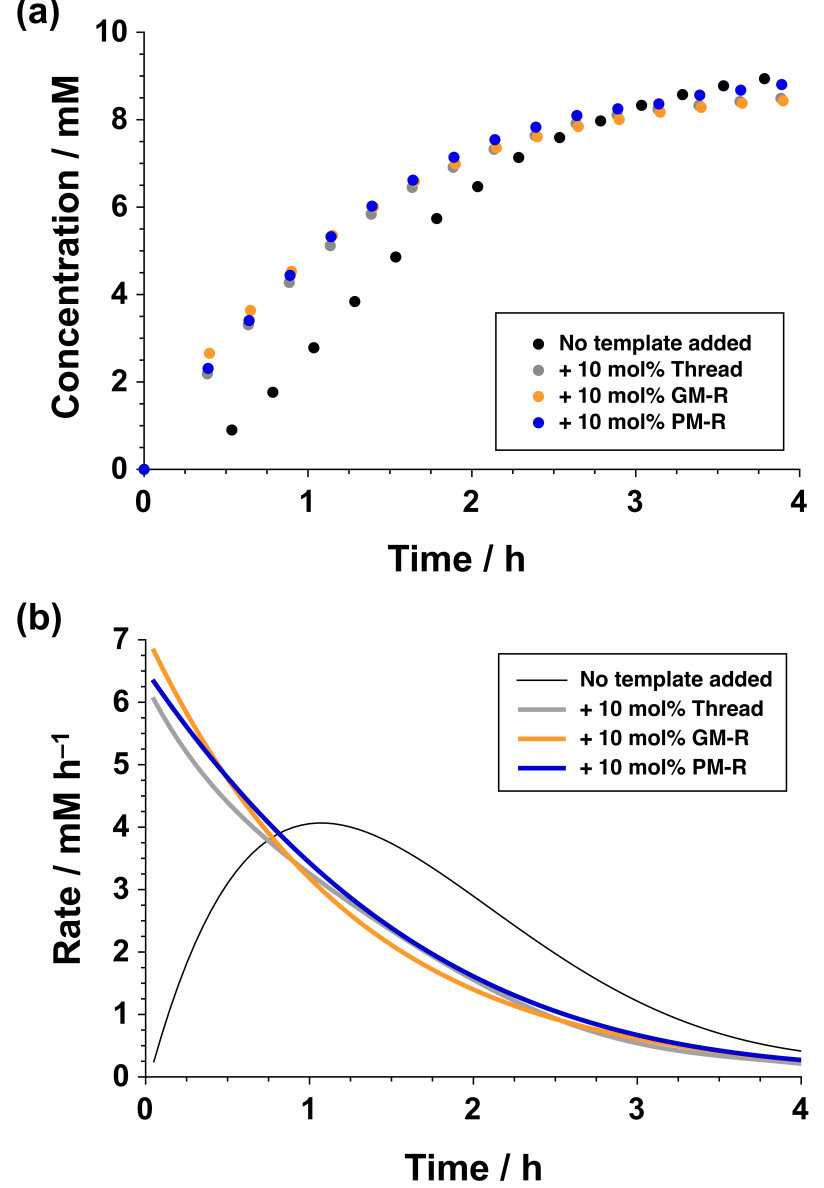

Figure 6. (a) Concentration and (b) rate profile for the formation of Thread in the absence of template (black) and in the presence of pre-formed thread (grey), 10 mol\% GM-R (orange) or 10 mol\% PM-R (blue) as determined by ${ }^{1} \mathrm{H}$ NMR spectroscopy $(500.1 \mathrm{MHz}$, $\mathrm{CDCl}_{3}, 5{ }^{\circ} \mathrm{C}$, all components at $10 \mathrm{mM}$ ). Concentration for each product was determined relative to 2,4-dinitrotoluene as an internal standard.

The concentration-time data for the GM-R and PM-R instructed thread kinetic experiments closely mirrored formation of thread in the presence of pre-formed thread template, showing clear disappearance of the lag period and shift in the time of maximum reaction rate (Figure $6 \mathrm{~b}$ ). The closely matching reaction profiles determined for the thread and $\mathbf{G M}-\mathbf{R}$ and $\mathbf{P M}-\mathbf{R}$ instructed kinetic experiments (max. rate 6.8 and $6.3 \mathrm{mM} \mathrm{h}^{-1}$, respectively) revealed that the thread is autocatalytic and the two rotaxanes are capable of crosscatalyzing thread formation with efficiency equal to that of thread. 
Having explored the thread kinetic pathways fully, we next examined the individual, uninstructed kinetics of GM-R (Figure 7) and PM-R (Figure 8). The progress of the rotaxane kinetic experiments was again followed by ${ }^{1} \mathrm{H}$ NMR spectroscopy, allowing us to deconvolute the individual proton resonances associated with the isoxazolidine ring of each thread and rotaxane product (for details, see ESI), which were formed with high diastereoselectivity for the trans cycloadducts.

(a)

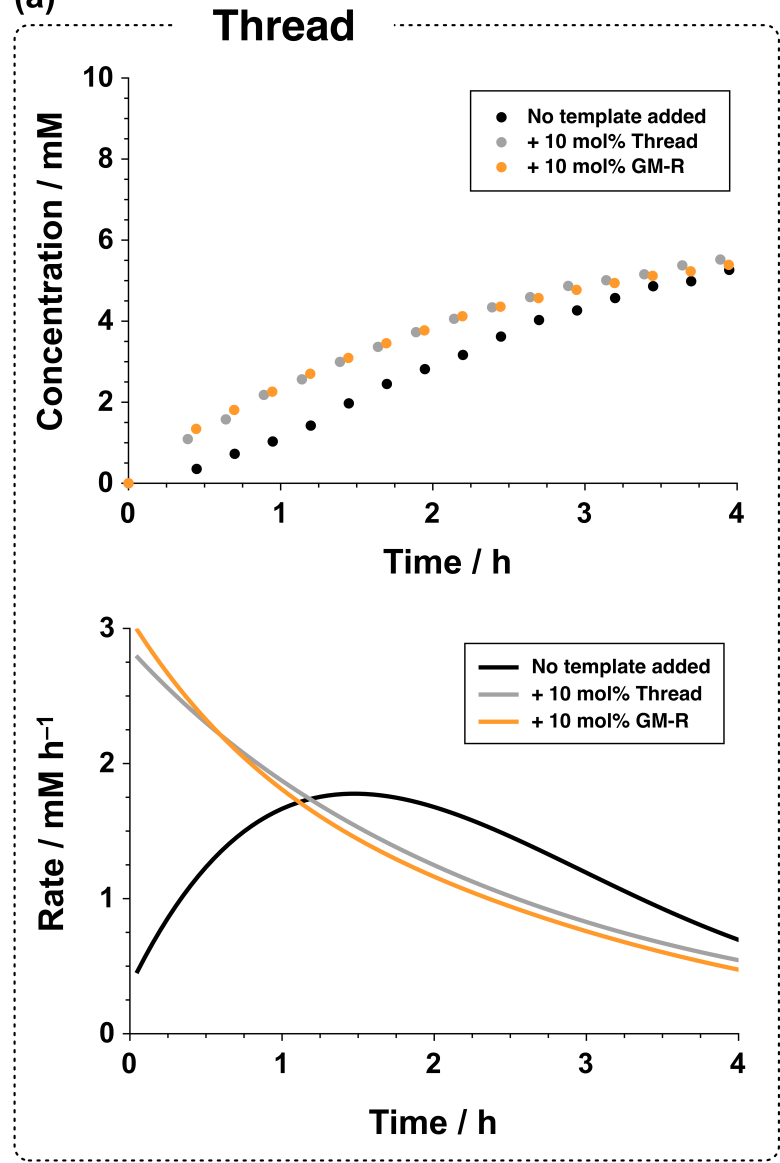

(b)
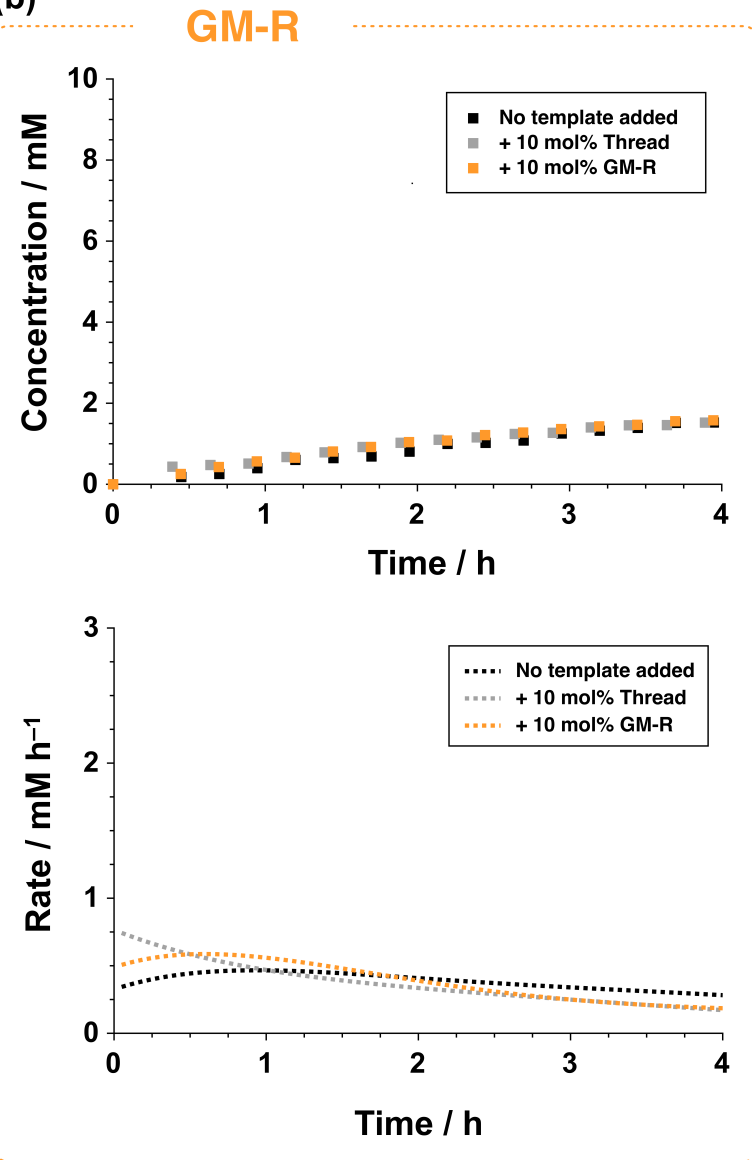

Figure 7. Concentration and rate profiles for the formation of (a) Thread (circles) and (b) GM-R (squares) in the GM [2]rotaxane kinetic experiments carried out in the absence of template (black) and in the presence of pre-formed 10 mol\% thread (grey) or 10 $\mathrm{mol} \% \mathrm{GM}-\mathbf{R}$ (orange) as determined by ${ }^{1} \mathrm{H}$ NMR spectroscopy $\left(500.1 \mathrm{MHz}, \mathrm{CDCl}_{3}, 5{ }^{\circ} \mathrm{C}\right.$, all components at $10 \mathrm{mM}$ ). Concentration for each product was determined relative to 2,4-dinitrotoluene as an internal standard.

After 4 hours, $\mathbf{T}$ reached a higher concentration than either rotaxane, resulting in a 1:3 ratio of GM-R:T and 1:2 of PM-R:T, reflecting the higher affinity of the linear guest for the pyridine macrocycle PM. As observed in the uninstructed thread experiment, the rotaxane reaction profiles in the absence of added template revealed catalysis, exhibiting an initial lag period and sigmoidal reaction profile. In the GM-R kinetic experiment, the maximum rate of product formation (Figure 7) was observed at 90 minutes $\left(1.78 \mathrm{mM} \mathrm{h}^{-1}\right)$ for thread and 57 minutes $\left(0.47 \mathrm{mM} \mathrm{h}^{-1}\right)$ for the rotaxane. Similarly, the maximum rate of thread formation in the PM-R experiment was determined at 87 minutes $\left(1.57 \mathrm{mM} \mathrm{h}^{-1}\right)$, and at 102 minutes $\left(0.60 \mathrm{mM} \mathrm{h}^{-1}\right)$ for the rotaxane (Figure 8). 
Figure 8. Concentration and rate profiles for the formation of (a) Thread (circles) and (b) PM-R (squares) in the PM [2]rotaxane kinetic experiments carried out in the absence of template (black) and in the presence of pre-formed $10 \mathrm{~mol} \%$ thread (grey) or 10 mol\% PM-R (blue) as determined by ${ }^{1} \mathrm{H}$ NMR spectroscopy $\left(500.1 \mathrm{MHz}, \mathrm{CDCl}_{3}, 5{ }^{\circ} \mathrm{C}\right.$, all components at $\left.10 \mathrm{mM}\right)$. Concentration for each product was determined relative to 2,4-dinitrotoluene as an internal standard.

The concentration-time profiles for the GM-R (Figure 7, top) and PM-R (Figure 8, top) rotaxane kinetic experiments in the presence of $10 \mathrm{~mol} \%$ of pre-formed instructing thread mirrored the corresponding profiles obtained in the rotaxane kinetic experiments instructed with GM-R or PM-R template very closely, exhibiting a nearly identical ratio of R:T and shortened lag period across each rotaxane set, as evidenced by the shift in maximum rate for the formation of thread and rotaxanes to an earlier time point (Figure 7 and 8 , bottom) in all instructed kinetic experiments. The outcome of the rotaxane kinetic experiments confirmed that both auto- and crosscatalytic cycles are operating in each rotaxane system with equal efficiency. Satisfyingly, results of the kinetic analyses confirmed that the orthogonal recognition processes enable formation of a replicating network where thread and rotaxane are matched in catalytic efficiencies as templates, in both auto- and crosscatalytic cycles. Nevertheless, the ratios of R:T determined in our kinetic experiments showed a strong preference for the formation of thread over the rotaxane in both replicating networks. This lower ratio indicates that while the pre-formed rotaxane templates are capable of catalyzing formation of both thread and rotaxane products efficiently, the rotaxane formation itself proceeds less effectively than we had hoped based on the low temperature pseudorotaxane experiments. 
One plausible explanation for the low efficiency of rotaxane formation and thus the low R:T ratio is the insufficient proportion of each reactive pseudorotaxane complex $[\mathbf{L} \cdot \mathbf{M}]_{\text {amide }}$ (Figure 9a), containing the macrocycle at the desired amide binding site, in each reaction as a result of the nitrone reactive site and amidopyridine recognition unit also associating with the macrocycles. The reactive pseudorotaxane complex $[\mathbf{L} \cdot \mathbf{M}]_{a m i d e}$ can react with stopper $\mathbf{S}$ through a bimolecular reaction $\left(k_{1}=k_{\mathrm{bi}}\right)$ and, in the presence of template, also through a recognition-mediated unimolecular reaction $\left(k_{2}=k_{\text {uni }}\right)$. By contrast, macrocycle bound at the nitrone reactive site results in formation of a pseudorotaxane $[\mathbf{L} \cdot \mathbf{M}]_{\text {nitrone }}$ (Figure $9 b$ ) that sequesters the $\mathbf{L}$ and $\mathbf{M}$ components in a co-conformation that hinders formation of any product. By contrast, association of the macrocycle with the amidopyridine recognition site, required for recognitionmediated self-replication, affords a pseudorotaxane complex $[\mathbf{L} \cdot \mathbf{M}]_{\text {amidopyridine }}$ (Figure 9c) that can only react through the bimolecular pathway $\left(k_{4}=k_{\mathrm{bi}}\right)$. Ultimately, the presence of these two additional sites on the linear component, capable of associating with the macrocycle, results in a smaller proportion of the desired pseudorotaxane complex $[\mathbf{L} \cdot \mathbf{M}]_{a m i d e}$, and, thus, a lower apparent $K_{a}$ for the pseudorotaxane formation. The apparent $K_{\mathrm{a}}$ reflects binding of the macrocycle to three different binding sites. Similarly, the observed unimolecular rate constant $\left(k_{\text {uni }}\right)$ associated with the template-mediated formation of each rotaxane is lower than it would be if the macrocycle was bound solely at the amide binding site.

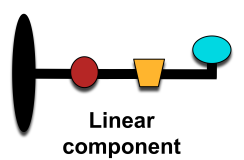

(a)
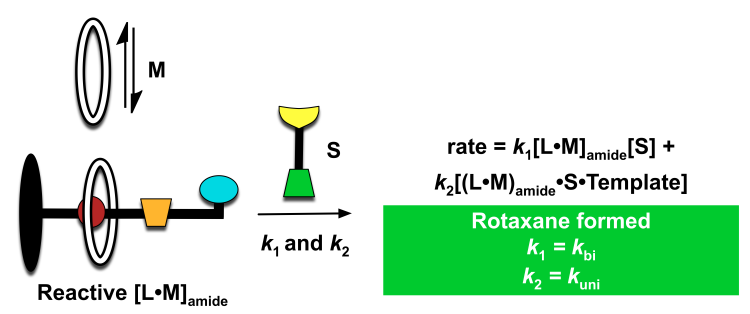

(b)

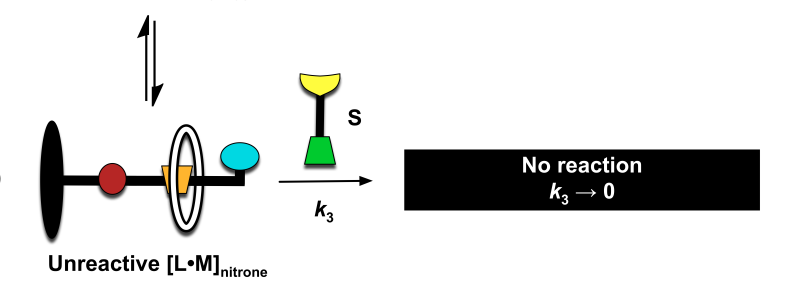

(c)

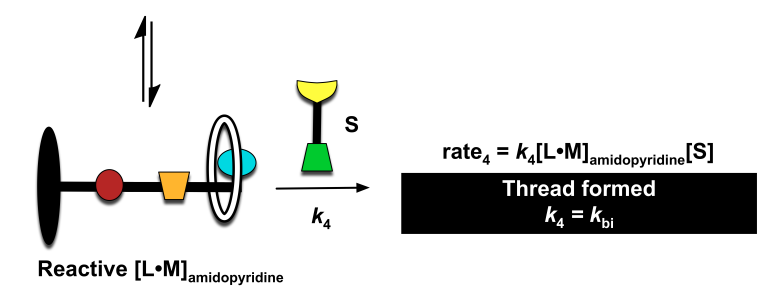

Figure 9. Model illustrating the association between macrocycle $\mathbf{M}$ and linear component $\mathbf{L}$, affording formation of three different pseudorotaxane complexes, only one of which results in the formation of the desired rotaxane. 
In order to gain a better understanding of the effect of additional binding sites on this highly interconnected system, we performed fitting of all of the concentration-time data available from the related thread and rotaxane kinetic experiments to kinetic models encompassing all interactions and reactions. These models included the formation of the three different pseudorotaxane complexes, in each system. Exploiting an appropriate fitting procedure (for details, see ESI), we were able to extract normally inaccessible kinetic parameters, namely, the template-mediated unimolecular rate constants $\left(k_{\text {uni }}\right)$ and the product duplex association constants ( $K_{\text {Duplex }}$ ) for the formation of Thread, GM-R and PM-R (Table 1). In order to avoid fitting a larger number of constants than the data sets available, we implemented two assumptions throughout the fitting procedure: (i) $k_{\mathrm{bi}}$ was assumed to be identical for all three templates and (ii) only a single $k_{\text {uni }}$ was fitted for each template across the auto- and crosscatalytic kinetic experiments forming a particular template. The latter assumption was based on the experimental observation of closely matched catalytic efficiencies determined during the kinetic experiments, and the fact that attempts to fit different unimolecular rate constants for the individual auto- and crosscatalytic pathways revealed little variation in the fitted values. Interestingly, the fitting revealed that $k_{\text {uni }}$ for the formation of both rotaxanes are, as a result of the binding between each macrocycle and the linear component, almost four times smaller that the $k_{\text {uni }}$ of thread. This difference reflects a decrease in the reactivity of the rotaxane-forming, catalytically-active quaternary complexes relative to the thread-forming ternary complexes. Using the fitted values of $k_{\mathrm{bi}}$ and $k_{\mathrm{uni}}$, the effective molarity ${ }^{20}$ for the formation of each template can be calculated. This parameter provides a measure of the efficiencies of the templatemediated catalytic pathways leading to the formation of thread and both rotaxanes, relative to the bimolecular pathways $\left(\mathrm{EM}=k_{\mathrm{uni}} / k_{\mathrm{bi}}\right)$. The apparent $K_{\mathrm{a}}$ values determined ${ }^{21}$ for the formation of $[\mathbf{L} \cdot \mathbf{G M}$ ] and $[\mathbf{L} \cdot \mathbf{P M}]$ pseudorotaxane complexes (Table 1) reflect the trend in association constants previously determined through low temperature experiments for $[\mathbf{N} \cdot \mathbf{M}]$.

Table 1. Kinetic parameters and association constants determined for the (i) formation of thread, (ii) formation of GM-R and (iii) PM-R, through kinetic simulation and fitting of experimental kinetic data (at $278 \mathrm{~K}$ ) using the SimFit software (Günter von Kiedrowski, University of Bochum, 2008). In all cases, the $K_{\mathrm{bi}}$ and $K_{\mathrm{a}}$ Duplex were determined as $1.04 \times 10^{-4} \mathrm{M}^{-1} \mathrm{~s}^{-1}$ and $10.3 \times 10^{6} \mathrm{M}^{-}$ ${ }^{1}$ for thread, GM-R and PM-R.

\begin{tabular}{cccc}
\hline & Thread & GM-R & PM-R \\
\hline${\text { Kunimolecular } / 10^{-4} \mathrm{~S}^{-1}}_{\text {Effective Molarity / M }}$ & 226 & 61.0 & 70.4 \\
$\boldsymbol{K}_{\mathbf{a}}[\mathrm{L} \cdot \mathrm{M}] / \mathrm{M}^{-1}$ & 217 & 59 & 68 \\
\hline
\end{tabular}

Analysis of the fitted kinetic parameters for thread and rotaxanes shows the detrimental effect of competitive macrocycle-binding sites on the apparent $K_{\mathrm{a}}$ for the formation of $[\mathbf{L} \cdot \mathbf{M}]$ and the unimolecular rate constant and consequently, the ratio of R:T formed in the system. In order to demonstrate how a similar system, integrating the formation of a rotaxane with self-replication, would work in the absence of competitive binding sites, we performed kinetic simulations. These simulations employed the parameters determined for PM-R system, which exhibits more efficient rotaxane formation than $\mathbf{G M}-\mathbf{R}$ as a result of a 
higher $K_{\mathrm{a}}$ for the $[\mathbf{L} \cdot \mathbf{M}]$. We specifically explored the effect of varying the strength of $[\mathbf{L} \cdot \mathbf{M}]$ associations constants from $10^{2}$ to $10^{5} \mathrm{M}^{-1}$ on the ratio of rotaxane:thread under two different conditions: condition $\mathrm{A}$ employed kinetic parameters determined for our experimental system ( $k_{\text {uni }}$ rotaxane $<k_{\text {uni }}$ thread); condition B examined an ideal system with no competitive macrocycle-binding sites on the linear component $\left(k_{\text {uni }}\right.$ rotaxane $=k_{\text {uni }}$ thread). Simulating condition B (Figure 10), where the effective molarity for thread and rotaxane are identical, allowed us to elucidate how the experimental system would behave in the absence of competitive binding sites - a situation where the ratio of products formed depends solely on the $K_{\mathrm{a}}$ governing the formation of $[\mathbf{L} \cdot \mathbf{M}]$.

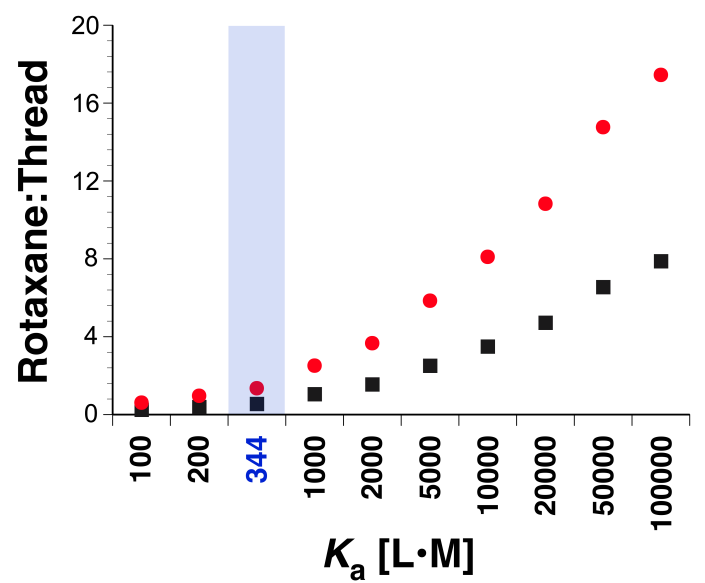

Figure 10. Outcome of kinetic simulations examining the effect of increasing $K_{a}$ for the formation of pseudorotaxane complex $[\mathbf{L} \cdot \mathbf{M}]$ on the ratio of rotaxane:thread formed in: condition $A(\boldsymbol{\Xi})$ employing kinetic parameters determined for our experimental system $\left(k_{\text {uni }}\right.$ rotaxane $<k_{\text {uni }}$ thread) and condition B $(\bullet)$ examining an ideal system with no competitive macrocyclebinding sites on the linear component $\left(k_{\text {uni }}\right.$ rotaxane $=k_{\text {uni }}$ thread). The blue rectangle represents the outcome of the simulation employing kinetic parameters determined for $\mathbf{T}$ and PM-R. Simulations were performed using SimFit software package (Günter von Kiedrowski, University of Bochum, 2008).

The results of the simulation (Figure 10, condition A) revealed that an increase in the $K_{\mathrm{a}}$ for the association between the linear component and macrocycle does not afford an R:T ratio greater than 8:1 in the condition employing experimental parameters, unless $K_{a}>10^{5} \mathrm{M}^{-1}$. While a considerable improvement over the current product ratios, it is possible that a larger $K_{a}$ value for the formation of pseudorotaxane $[\mathbf{L} \cdot \mathbf{M}]$ might also result in a concurrent increase in the strength of association for the macrocycle binding sites (see Figure 9), therefore, resulting in a lower R:T ratio than predicted from this simulation. Whilst the current experimental design, incorporating two additional competing macrocyclebinding sites, does not favor rotaxane formation, the same kinetic model can afford significantly higher $\mathbf{R}: \mathbf{T}$ ratios (>15:1) if only a single, desired macrocycle binding site is present (Condition $B$ ), demonstrating that rotaxane can be formed selectively in a replicating network operating simultaneously through both auto- and crosscatalytic pathways. 


\section{Conclusions}

In conclusion, we have described a successful experimental implementation and full characterization of a reaction network integrating replication processes with the assembly of a [2]rotaxane. Through the application of orthogonal recognition processes, we were able to effectively direct formation of a replicating network where thread and rotaxane products are matched in catalytic efficiencies as templates, in both auto- and crosscatalytic cycles. However, interplay between the different recognition and reactive processes in the complex network, specifically the nitrone and amidopyridine moieties acting as competitive binding sites for the macrocyclic component, resulted in thread formation surpassing rotaxane formation in the current experimental system. Exploiting kinetic simulations, we demonstrated that orthogonal recognition processes are capable of driving autocatalytic rotaxane formation in the absence of competitive macrocycle binding sites. The realization of this goal is currently under investigation in our laboratory.

\section{Acknowledgements}

The financial support for this work was provided by EPSRC (Grant EP/K503162/1 and EP/E017851/1) and the Ministry for Higher Education Malaysia. The research data supporting this publication can be accessed at http://dx.doi.org/10.17630/d115d058-349e-4300-94e3-76a3181a9fc7.

Electronic Supplementary Information (ESI) available: experimental procedures, details of kinetic measurements, binding studies, computational modeling of the thread:rotaxane network, example fitting and simulation scripts.

\section{References and Footnotes}

(1) (a) Whitesides, G. M.; Boncheva, M. Proc. Natl. Acad. Sci. U. S. A. 2002, 99, 4769. (b) Whitesides, G. M.; Grzybowski, B. Science 2002, 295, 2418. (c) Greig, L. M.; Philp, D. Chem. Soc. Rev. 2001, 30, 287. (d) Klug, A. Philos. Trans. R. Soc. Lond. B. Biol. Sci. 1999, 354, 531. (e) Philp, D.; Stoddart, J. F. Angew. Chem. Int. Ed. Engl. 1996, 35, 1154. (f) Whitesides, G. M.; Mathias, J. P.; Seto, C. T. Science 1991, 254, 1312. (g) Kushner, D. J. Bacteriol. Rev. 1969, 33, 302.

(2) (a) Lista, M.; Orentas, E.; Areephong, J.; Charbonnaz, P.; Wilson, A.; Zhao, Y.; Bolag, A.; Sforazzini, G.; Turdean, R.; Hayashi, H.; Domoto, Y.; Sobczuk, A.; Sakai, N.; Matile, S. Org. Biomol. Chem. 2013, 11, 1754. (b) Salles, A. G.; Zarra, S.; Turner, R. M.; Nitschke, J. R. J. Am. Chem. Soc. 2013, 135, 19143. (c) Northrop, B. H.; Zheng, Y.-R.; Chi, K.-W.; Stang, P. J. Acc. Chem. Res. 2009, 42, 1554. (d) Halley, J. D.; Winkler, D. A. Complexity 2008, 14, 10. (e) Karsenti, E. Nat. Rev. Mol. Cell Biol. 2008, 9, 255. (f) Epstein, I. R.; Pojman, J. A.; Steinbock, O. Chaos 2006, 16, 037101. (g) Nédélec, F. J.; Surrey, T.; Maggs, A. C.; Leibler, S. Nature 1997, 389, 305.

(3) (a) Pearson, R. J.; Kassianidis, E.; Slawin, A. M. Z.; Philp, D. Chem. Eur. J. 2006, 12, 6829. (b) Pearson, R. J.; Kassianidis, E.; Slawin, A. M. Z.; Philp, D. Org. Biomol. Chem. 2004, 2, 3434.

(4) (a) Lehn, J.-M. Angew. Chem. Int. Ed. 2013, 52, 2836. (b) Campbell, V.; Nitschke, J. R. Synlett 2008, 20, 3077. (c) Lehn, J.-M. Chem. Soc. Rev. 2007, 36, 151. (d) Lehn, J.-M. Science 2002, 295, 2400.

(5) (a) Chambron, J.-C.; Sauvage, J.-P. New J. Chem. 2013, 37, 49. (b) Tiefenbacher, K.; Ajami, D.; Rebek, J. Jr. Angew. Chem. Int. Ed. 2011, 50, 12003. (c) Chichak, K. S.; Cantrill, S. J.; Pease, a. R.; Chiu, S. H.; Cave, G. W. V.; Atwood, J. L.; Stoddart, J. F. Science 2004, 304, 1308. (d) Yan, H.; Park, S. H.; Finkelstein, G.; Reif, J. H.; LaBean, T. H. Science 2003, 301, 1882. (e) Beijer, F. H.; Kooijman, H.; 
Spek, A. L.; Sijbesma, R. P.; Meijer, E. W. Angew. Chem. Int. Ed. 1998, 37, 75. (f) Mao, C.; Sun, W.; Seeman, N. C. Nature 1997, 386, 137. (g) Mirkin, C. A.; Letsinger, R. L.; Mucic, R. C.; Storhoff, J. J. Nature. 1996, 607. (h) Harada, A.; Li, J.; Kamachi, M. Nature 1992, 356, 325.

(6) (a) Gil-Ramírez, G.; Leigh, D. A.; Stephens, A. J. Angew. Chem. Int. Ed. 2015, 54, 6110. (b) Niess, F.; Duplan, V.; Diercks, C. S.; Sauvage, J.-P. Chem. Eur. J. 2015, 21, 14393. (c) Durot, S.; Heitz, V.; Sour, A.; Sauvage, J.-P. Top. Curr. Chem. 2014, 354, 35. (d) Leigh, D. A.; Marcos, V.; Wilson, M. R. ACS Catal. 2014, 4, 4490. (e) Leigh, D. A.; Pritchard, R. G.; Stephens, A. J. Nat. Chem. 2014, 6, 978. (f) Barin, G.; Coskun, A.; Fouda, M. M. G.; Stoddart, J. F. Chempluschem. 2012, 77, 159. (g) Beves, J. E.; Blight, B. A.; Campbell, C. J.; Leigh, D. A.; McBurney, R. T. Angew. Chem. Int. Ed. 2011, 50, 9260. (h) Stoddart, J. F. Chem. Soc. Rev. 2009, 38, 1802. (i) Haussmann, P. C.; Stoddart, J. F. Chem. Rec. 2009, 9, 136. (j) Griffiths, K. E.; Stoddart, J. F. Pure Appl. Chem. 2008, 80, 485. (k) Stoddart, J. F.; Tseng, H.-R. Proc. Natl. Acad. Sci. U. S. A. 2002, 99, 4797.

(7) (a) Kay, E. R.; Leigh, D. A. Angew. Chem. Int. Ed. 2015, 54, 2. (b) de Bo, G.; Kuschel, S.; Leigh, D. A.; Lewandowski, B.; Papmeyer, M.; Ward, J. W. J. Am. Chem. Soc. 2014, 136, 5811. (c) Carlone, A.; Goldup, S. M.; Lebrasseur, N.; Leigh, D. A.; Wilson, A. J. Am. Chem. Soc. 2012, 134, 8321. (d) Kay, E. R.; Leigh, D. A.; Zerbetto, F. Angew. Chem. Int. Ed. 2007, 46, 72. (e) Vicario, J.; Katsonis, N.; Ramon, B. S.; Bastiaansen, C. W. M.; Broer, D. J.; Feringa, B. L. Nature 2006, 440, 163. (f) Schalley, C. A.; Beizai, K.; Vögtle, F. Acc. Chem. Res. 2001, 34, 465. (g) Raehm, L.; Kern, J.-M.; Sauvage, J.-P. Chem. Eur. J. 1999, 5, 3310. (h) Gómez-López, M.; Preece, J. A.; Stoddart, J. F. Nanotechnology 1999, 7, 183. (i) Balzani, V.; Gomez-Lopez, M.; Stoddart, J. F. Acc. Chem. Res. 1998, 31, 405.

(8) (a) Plöger, T. A.; von Kiedrowski, G. Org. Biomol. Chem. 2014, 12, 6908. (b) Robertson, M. P.; Joyce, G. F. Chem. Biol. 2014, 21, 238. (c) Carnall, J. M. A.; Waudby, C. A.; Belenguer, A. M.; Stuart, M. C. A.; Peyralans, J. J.-P.; Otto, S. Science 2010, 327, 1502. (d) Kassianidis, E.; Philp, D. Angew. Chem. Int. Ed. 2006, 45, 6344. (e) Paul, N.; Joyce, G. F. Proc. Natl. Acad. Sci. U. S. A. 2002, 99, 12733. (f) Allen, V. C.; Philp, D.; Spencer, N. Org. Lett. 2001, 3, 777. (g) Wang, B.; Sutherland, I. O. Chem. Commun. 1997, 1495. (h) Lee, D. H.; Granja, J. R.; Martinez, J. A.; Severin, K.; Ghadri, M. R. Nature. 1996, 525. (i) Terfort, A.; von Kiedrowski, G. Angew. Chem. Ed. Engl. 1992, 31, 654. (j) Rotello, V.; Hong, J.-I.; Rebek, J. Jr. J. Am. Chem. Soc 1991, 113, 9422. (k) Tjivikua, T.; Ballester, P.; Rebek, J. Jr. J. Am. Chem. Soc. 1990, 112, 1249. (I) Zielinski, W. S.; Orgel, L. E. Nature 1987, 327, 346. (m) von Kiedrowski, G. Angew. Chem. Int. Ed. Engl. 1986, 25, 932.

(9) (a) Ruiz-Mirazo, K.; Briones, C.; de la Escosura, A. Chem. Rev. 2014, 114, 285. (b) Root-Bernstein, R. Acc. Chem. Res. 2012, 45, 2169. (c) Nitschke, J. R. Nature 2009, 462, 736. (d) Eschenmoser, A. Tetrahedron 2007, 63, 12821. (e) Stankiewicz, J.; Eckardt, L. H. Angew. Chem. Int. Ed. 2006, 45, 342.

(10) (a) Mahon, C. S.; Fulton, D. a. Nat. Chem. 2014, 6, 665. (b) Giuseppone, N. Acc. Chem. Res. 2012, 45, 2178. (c) Balazs, A. C.; Epstein, I. R. Science 2009, 325, 1632. (d) Pross, A. Orig. Life Evol. Biosph. 2005, 35, 151. (e) Epstein, I. R.; Showalter, K. J. Chem. Phys. 1996, 100, 13132.

(11) (a) Vidonne, A.; Philp, D. Eur. J. Org. Chem. 2009, 2009, 593. (b) Patzke, V.; von Kiedrowski, G. ARKIVOC 2007, 5, 293.

(12) Vidonne, A.; Philp, D. Tetrahedron 2008, 64, 8464.

(13) Sadownik, J. W.; Philp, D. Angew. Chem. Int. Ed. 2008, 47, 9965.

(14) (a) Liu, P.; Li, W.; Liu, L.; Wang, L.; Ma, J. J. Phys. Chem. A 2014, 118, 9032. (b) Liu, L.; Liu, Y.; Liu, P.; Wu, J.; Guan, Y.; Hu, X.; Lin, C.; Yang, Y.; Sun, X.; Ma, J.; Wang, L. Chem. Sci. 2013, 4, 1701. (c) Hassan, N. I.; del Amo, V.; Calder, E.; Philp, D. Org. Lett. 2011, 13, 458. (d) Hsueh, S.-Y.; Kuo, C.-T.; Lu, T.-W.; Lai, C.-C.; Liu, Y.-H.; Hsu, H.-F.; Peng, S.-M.; Chen, C.-H.; Chiu, S.-H. Angew. Chem. Int. Ed. 2010, 49, 9170. (e) Hung, W.-C.; Wang, L.; Lai, C.-C.; Liu, Y.-H.; Peng, S.-M.; Chiu, S.-H. Tetrahedron Lett. 2009, 50, 267. (f) Huang, Y. L.; Hung, W.-C.; Lai, C.-C.; Liu, Y.-H.; Peng, S.-M.; Chiu, S.-H. Angew. Chem. Int. Ed. 2007, 46, 6629.

(15) Ho, T.-H.; Lai, C.-C,; Liu, Y.-H.; Peng, S.-M.; Chiu, S.-H. Chem. Eur. J. 2014, 20, 4563.

(16) Jager, R.; Baumann, S.; Fischer, M.; Safarowsky, O.; Niegerb, M.; Vogtle, F. Liebigs Ann. 1997, 2269.

(17) (a) D'Souza, D. M.; Leigh, D. A.; Mottier, L.; Mullen, K. M.; Paolucci, F.; Teat, S. J.; Zhang, S. J. Am. Chem. Soc. 2010, 132, 9465. (b) O’Neil, I. A.; Potter, A. J.; Southern, J. M.; Steiner, A.; Barkley, J. V. Chem. Commun. 1998, 2511.

(18) Suitable single crystals were grown as colorless needles by slow evaporation of acetonitrile/CDCl 3 (GM [2]rotaxane) or as plates by slow evaporation from acetonitrile (PM [2]rotaxane). For more details, see ESI. 
(19) The recognition-disabled, bimolecular reactions to form thread and both rotaxane from the linear component $\mathbf{L}$ and a $p$-methyl substituted maleimide $\left(\mathbf{S}_{\text {dis }}\right)$ showed low conversion and low diastereoselectivity (for details, see ESI).

(20) (a) Page, M. I.;, Jencks, W. P. Proc. Natl. Acad. Sci. U. S. A. 1971, 68, 1678. (b) Page, M. I. Chem. Soc. Rev. 1973, 2, 295. (c) Kirby, A. J. Adv. Phys. Org. Chem. 1980, 17, 183.

(21) Throughout the fitting process, only a single $K_{\mathrm{a}}$ value was fitted for all three processes leading to the formation of the different pseudorotaxane complexes: $[\mathbf{L} \cdot \mathbf{M}]_{\text {amide, }},[\mathbf{L} \cdot \mathbf{M}]_{\text {nitrone, }}[\mathbf{L} \cdot \mathbf{M}]_{\text {amidopyridine. }}$ While the $K_{\mathrm{a}}$ governing the formation of each pseudorotaxane complex might be different, we were unable to deconvolute the three individual binding events. Therefore, in order to avoid using an inappropriately large number of variable parameters during fitting, only one association constant for the three binding processes was fitted (see fitting script in the ESI). 


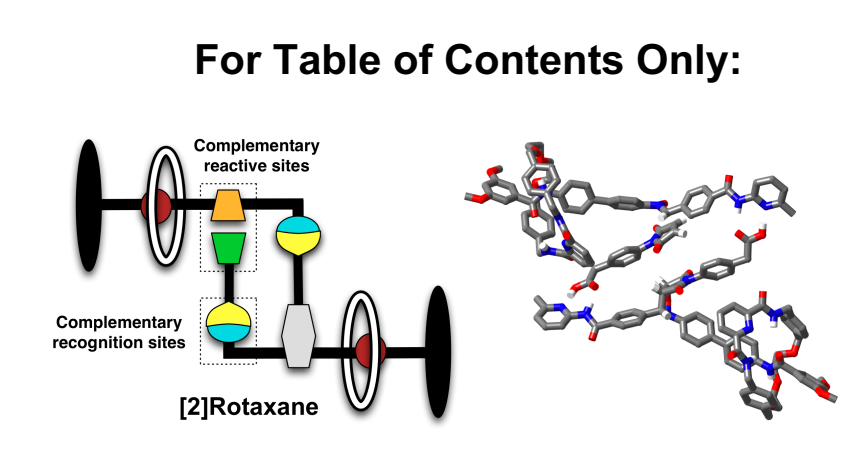

